\title{
Changes in Morphological Characteristics, Regeneration Ability, and Polysaccharide Content in Tetraploid Dendrobium officinale
}

Phu-Long Pham, Ying-Xue Li, He-Rong Guo, Rui-Zhen Zeng, Li Xie, and Zhi-Sheng Zhang

Guangdong Key Laboratory of Plant Molecular Breeding, College of Forestry and Landscape Architecture, South China Agricultural University, Guangzhou, Guangdong 510642, China

\section{Jianjun Chen}

Environmental Horticulture Department and Mid-Florida Research and Education Center, IFAS, University of Florida, Gainesville, FL 32703

\section{Qing-Lian Su and Qing Xia}

Guangzhou Flower Research Center, Guangzhou, Guangdong 510360, China

Additional index words. chromosome doubling, colchicine, Dendrobium polysaccharide, orchids, protocorm-like bodies

\begin{abstract}
Dendrobium officinale Kimura et Migo is a famous traditional Chinese medicinal plant. It produces various phytochemicals, particularly polysaccharides, which have nutraceutical and pharmaceutical values. To increase its biomass production and polysaccharide content, our breeding program has generated a series of polyploid cultivars through colchicine treatment of protocorm-like bodies (PLBs). The present study compared two tetraploid cultivars, 201-1- $\mathrm{T}_{1}$ and 201-1-T $\mathrm{T}_{2}$, with their diploid parental cultivar, 201-1, in an established in vitro culture system. Tetraploid ' 201-1- $T_{1}$ ' and '201-1- $\mathrm{T}_{2}$ ' had shorter leaves and shorter and thicker stems and roots, and they produced higher biomass compared with the diploid cultivar. The length and width of stomata significantly increased, but stomatal density decreased in tetraploid cultivars. The PLB induction rates from the stem node explants of the tetraploid cultivars were significantly higher than those of diploid. However, the PLB proliferation of tetraploids was lower than that of the diploid. The mean number of plantlets regenerated from tetraploid PLBs was also lower than that of the diploid after 4 months of culture. Polysaccharide contents in stems, leaves, and roots of 6-month-old tetraploid plantlets were significantly higher than those of diploids. The polysaccharide content in the stem of '201-1-T,' was $12.70 \%$, which was a 2 -fold increase compared with the diploid cultivar. Our results showed that chromosome doubling could be a viable way of improving $D$. officinale in biomass and polysaccharide production.
\end{abstract}

Dendrobium Sw. is one of the largest genera in the family Orchidaceae, and it comprises more than 1500 species (Cheng et al., 2019) that are widely distributed in Asia, Australia, and Europe and produced as ornamental flowering plants (Lam et al., 2015). In China, Dendrobium, commonly known as "Shi Hu," has been used as traditional Chinese medicine for thousands of years (Cheng et al., 2019). More than 78 species of Dendrobium are native to China,

Received for publication 21 June 2019. Accepted for publication 2 Aug. 2019.

This work was supported by the Science and Technology Planning Project of Guangdong Province, China (2015A020209118 and 2015A030302066) and the China Scholarship Council.

L.X. and Z.-S.Z. are corresponding authors. E-mail: xieli@scau.edu.cn or zszhang@scau.edu.cn. and 50 of them have medicinal value (Chen et al., 2012; Xu et al., 2013). They are a source of tonic, astringent, analgesic, antipyretic, and anti-inflammatory substances (Cakova et al., 2017). Regarded as one of the most famous Dendrobium in China since the Tang dynasty $\approx 1300$ years ago, $D$. officinale Kimura et Migom has been used to eliminate heat evil, remediate stomach problems, moisten the lung, relieve cough, nourish the body, and prolong lifespan (Alonso-Sande et al., 2009; Wang et al., 2018; Yuan et al., 2014). More than 190 compounds have been isolated from $D$. officinale (Tang et al., 2017), of which polysaccharide is one of the major active constituents, exhibiting immunomodulatory and cardioprotective activities (Dou et al., 2016; He et al., 2016). Stems usually contain a high concentration of polysaccharide (He et al., 2017). Due to its health benefits and long growth cycle, wild $D$. officinale has been exploited to near extinction. D. officinale has been considered a threatened species and is listed as critically endangered on the International Union for Conservation of Nature (IUCN) Red List (Critically Endangered A4c ver. 3.1) (Jin et al., 2016; Qian et al., 2014). Despite previous attempts to revive $D$. officinale, an urgent need for conserving wild $D$. officinale still exists (Li et al., 2018a; Liu et al., 2015; Teixeira da Silva et al., 2014b). To meet the demand for commercial production, new cultivars should be developed and methods for efficient propagation should be established (Ding et al., 2008).

Current efforts regarding $D$. officinale breeding include germplasm collection, identification, evaluation, and conventional hybridization. Breeding objectives are largely focused on improving morphological characteristics and biomass production (Teixeira da Silva et al., 2016). Only a limited number of cultivars have been released thus far (Chen et al., 2018). Chromosome manipulation is an effective way of orchid improvement (Hossain et al., 2013). Because orchid seeds produce protocorm during germination, and because in vitro regeneration induces protocorm-like bodies (PLBs) (Morel, 1960; Teixeira da Silva et al., 2015), protocorms or PLBs can be easily treated with colchicine for manipulation of chromosomes (Yang et al., 2013; Zhan and Cheng, 2011). PLBs are composed of many meristematic centers that differentiate into shoots and roots (Cui et al., 2008). An advantage of propagation through PLBs is that a large number of plantlets can be regenerated, thus enhancing propagation efficiency (Chen and Wei, 2018). Through colchicine treatment, autopolyploids have been induced from several Dendrobium species, including D. chrysotoxum (Atichart, 2013), D. devonianum (Li et al., 2005), D. nobile (Vichiato et al., 2014), D. ochreatum (Wang et al., 2017), and D. officinale (Yang et al., 2013; Zhan and Cheng, 2011). Autopolyploidy results in more floral pieces with larger petals and/or sepals, prolonged flower lifespan, and increased fertility (Chaicharoen, 1995; Chaicharoen and Saejew, 1981; Ketsa et al., 2001; McConnell and Kamemoto, 1993; Vichiato et al., 2014). Furthermore, autopolyploidy enhances plant overall size, including increased leaf width and thickness and biomass production (Chaicharoen and Saejew, 1981; del Pozo and Ramirez-Parra, 2014; Dudits et al., 2016; Jiang et al., 2014; Vichiato et al., 2007).

Chromosome manipulation of $D$. officinale has been primarily centered on morphological changes, and limited attention has been given to the regeneration ability during in vitro culture and active phytochemicals such as polysaccharide. We believe that in addition to morphological changes, polyploidized $D$. officinale, such as tetraploids, should have increased contents of polysaccharide and exhibit differences in plant regeneration during in vitro culture. Our breeding program has produced a series of D. officinale cultivars with different ploidy 
levels. The present study was performed to test our hypothesis by comparing two tetraploid cultivars, 201-1- $\mathrm{T}_{1}$ and 201-1- $\mathrm{T}_{2}$, with their parental diploid cultivar, 201-1, and to determine if morphological characteristics, regeneration ability, and polysaccharide content were changed due to the induced autopolyploidization.

\section{Materials and Methods}

Plant materials. Diploid D. officinale hybrid 201-1 $(2 n=38)$ and tetraploid cultivars $201-1-\mathrm{T}_{1}$ and $201-1-\mathrm{T}_{2}(2 n=76)$ were used in this study. Their appearance, root tip cell chromosome numbers, and relative DNA contents that were analyzed using flow cytometry (Cui et al., 2009) are presented in Fig. 1. The two tetraploids were selected from a regenerated population of '201-1' after the PLBs were treated with colchicine.
Hybrid 201-1 has a rapid growth rate and a desirable growth form, and it has been used as a new cultivar. The two tetraploids have been stable during in vitro culture and in greenhouse production.

Analysis of morphological characteristics. Young shoots $(\approx 1 \mathrm{~cm})$ derived from PLBs were grown in glass culture vessels (height, $100 \mathrm{~mm}$; diameter, $65 \mathrm{~mm}$; and volume, $330 \mathrm{~mL}$ ) containing MS medium (Murashige and Skoog, 1962) supplemented with $2.2 \mu \mathrm{M}$ 6-BA (6-benzylaminopurine), $0.5 \mu \mathrm{M}$ NAA (naphthaleneacetic acid), $30 \mathrm{~g} \cdot \mathrm{L}^{-1}$ sucrose, $0.3 \mathrm{~g} \cdot \mathrm{L}^{-1}$ active carbon (AC), and $7 \mathrm{~g} \cdot \mathrm{L}^{-1}$ agar with a $\mathrm{pH}$ of 5.8. There were five shoots per culture vessel and nine vessels per cultivar. The experiment was arranged as a randomized complete block design (RCBD). Each culture vessel was considered an experimental unit, each block had three vessels per cultivar, and there were three blocks.
Young shoots were maintained in a culture room under fluorescent tube with a light intensity of $20 \mu \mathrm{mol} \cdot \mathrm{m}^{-2} \cdot \mathrm{s}^{-1}$. Six months after culture, plantlet height, stem diameter, leaf number, leaf width and length, root number, root length, and diameter were recorded using an electronic digital caliper. The fresh weight of entire plantlets, after roots were washed to remove agar and blotted on paper towels, was weighed using an electronic balance.

Determination of stomatal dimension and density. Another experiment that was identical to the aforementioned morphological analysis was conducted, but it was used to analyze stomatal dimension and density based on the method described by Stoddard (1965). Briefly, a drop of clear nail polish was applied to the abaxial surface of the third leaf from the meristem per plantlet. After drying, a piece of Scotch $3 \mathrm{M}$ transparent tape (Scotch
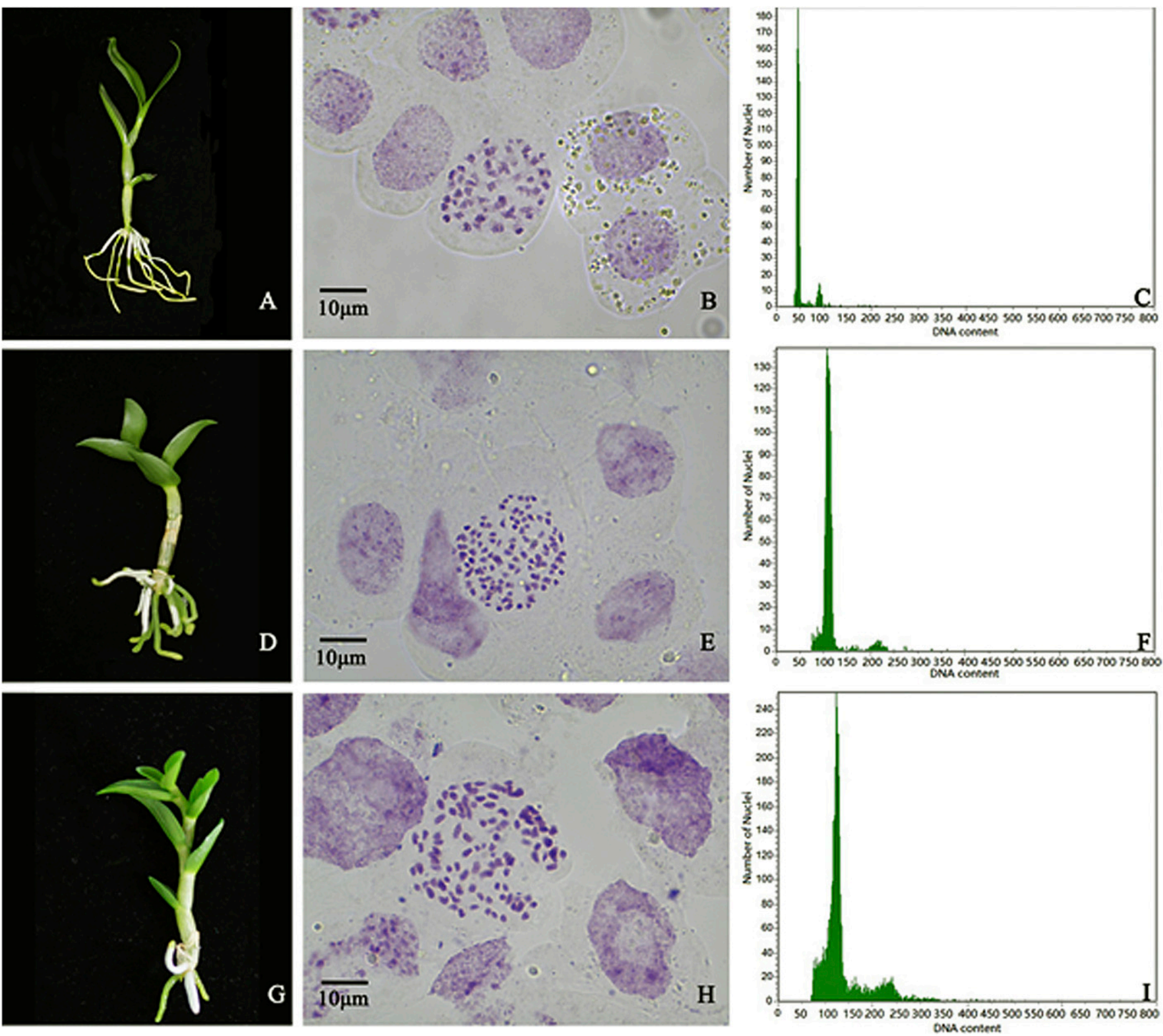

Fig. 1. The plantlet appearance, chromosome number in root tip cell, and relative DNA content in leaves of the diploid (2n=38) parental cultivar 201-1 (A-C) and two tetraploid $(2 n=76)$ cultivars 201-1- $\mathrm{T}_{1}(\mathbf{D}-\mathbf{F})$ and 201-1- $\mathrm{T}_{2}(\mathbf{G}-\mathbf{I})$ of $D$. officinale. 
3M, St. Paul, MN) was placed on top of dried nail polish. The polish with an imprint affixed to the tape was peeled off and mounted on the microscope slides for observation. Stomata were viewed using a compound biological microscope, and the images were displayed on a computer via the microscope's built-in camera (Moticam2306; 3.0 M Pixel USB 2.0) with Motic Images Advanced 3.2 software (Motic Group, Hong Kong, China). Digital images of the leaf and stomata imprints were viewed at $400 \times$ and $1000 \times$ magnification and saved as a digital tagged image file (.tif) with $1024 \times 768$-pixel resolution for the later analysis. The images of the leaf imprint were analyzed, and the stomatal lengths were

Table 1. Morphological and stomatal characteristics of diploid and tetraploid cultivars of D. officinale grown under in vitro culture conditions. ${ }^{z}$

\begin{tabular}{lccr}
\hline Parameter & Diploid 201-1 & Tetraploid 201-1- $\mathrm{T}_{1}$ & Tetraploid 201-1- $\mathrm{T}_{2}$ \\
\hline Stem length $(\mathrm{cm})$ & $5.43 \pm 0.36 \mathrm{a}^{\mathrm{y}}$ & $4.20 \pm 0.17 \mathrm{~b}$ & $3.03 \pm 0.24 \mathrm{c}$ \\
Stem diameter $(\mathrm{cm})$ & $0.28 \pm 0.02 \mathrm{~b}$ & $0.42 \pm 0.02 \mathrm{a}$ & $0.44 \pm 0.03 \mathrm{a}$ \\
Leaf no. & $5.70 \pm 0.49 \mathrm{a}$ & $5.40 \pm 0.47 \mathrm{a}$ & $4.80 \pm 0.35 \mathrm{a}$ \\
Leaf length $(\mathrm{cm})$ & $2.14 \pm 0.11 \mathrm{a}$ & $1.55 \pm 0.09 \mathrm{~b}$ & $1.29 \pm 0.37 \mathrm{c}$ \\
Leaf width $(\mathrm{cm})$ & $0.78 \pm 0.04 \mathrm{a}$ & $0.77 \pm 0.03 \mathrm{a}$ & $0.73 \pm 0.05 \mathrm{a}$ \\
Root no. & $6.30 \pm 0.63 \mathrm{a}$ & $7.00 \pm 0.95 \mathrm{a}$ & $7.20 \pm 0.35 \mathrm{a}$ \\
Root length $(\mathrm{cm})$ & $5.74 \pm 0.38 \mathrm{a}$ & $2.24 \pm 0.13 \mathrm{~b}$ & $2.17 \pm 0.14 \mathrm{~b}$ \\
Root diameter $(\mathrm{cm})$ & $0.13 \pm 0.006 \mathrm{~b}$ & $0.19 \pm 0.007 \mathrm{a}$ & $0.21 \pm 0.007 \mathrm{a}$ \\
Fresh weight $(\mathrm{g})$ & $0.92 \pm 0.07 \mathrm{~b}$ & $2.14 \pm 0.17 \mathrm{a}$ & $1.95 \pm 0.57 \mathrm{a}$ \\
Stomata no. $\left(1000 \mu \mathrm{mm}^{2}\right)$ & $54.40 \pm 0.83 \mathrm{a}$ & $30.30 \pm 1.76 \mathrm{~b}$ & $30.50 \pm 0.76 \mathrm{~b}$ \\
Stomata cell length $(\mu \mathrm{m})$ & $37.36 \pm 0.67 \mathrm{c}$ & $45.99 \pm 0.74 \mathrm{a}$ & $42.13 \pm 0.64 \mathrm{~b}$ \\
Stomata cell width $(\mu \mathrm{m})$ & $19.10 \pm 0.26 \mathrm{c}$ & $25.53 \pm 1.28 \mathrm{a}$ & $22.26 \pm 0.74 \mathrm{~b}$ \\
Stomata area $\left(\mu \mathrm{m}^{2}\right)$ & $1535.31 \pm 37.33 \mathrm{~b}$ & $2392.45 \pm 123.78 \mathrm{a}$ & $2172.37 \pm 90.16 \mathrm{a}$ \\
\hline
\end{tabular}

${ }^{\mathrm{z}}$ All data represent means $\pm \mathrm{SE}(\mathrm{n}=3)$.

${ }^{\mathrm{y}}$ Different letters within the same row indicate a significant difference at $P \leq 0.05$ based on Duncan's multiple range test.

measured using Image $\mathrm{J} 2$ software. Fifteen

Evaluation of $P L B$ induction, proliferation, and plant regeneration. Stems $\approx 4$ to $5 \mathrm{~cm}$ in length were cut from '201-1', '201-1- $\mathrm{T}_{1}$ ', and '201-1- $\mathrm{T}_{2}$ ' plantlets. After removal of leaves, the stems were decontaminated with $70 \%$ ethanol for $\approx 1 \mathrm{~min}$. Then, they were thoroughly rinsed with sterilized distilled water for $30 \mathrm{~s}$. Finally, they were cut into segments $\approx 0.4$ to $0.5 \mathrm{~cm}$ in length and inoculated on half-strength MS medium supplemented with $0.44 \mu \mathrm{M}$ 6-BA, $20 \%$ coconut water $(\mathrm{CW}), 30 \mathrm{~g} \cdot \mathrm{L}^{-1}$ sucrose, $7 \mathrm{~g} \cdot \mathrm{L}^{-1}$ agar, and $0.1 \mathrm{~g} \cdot \mathrm{L}^{-1} \mathrm{AC}$ with a $\mathrm{pH}$ of 5.8 . The

experiment was also set as an RCBD. Each images per cultivar were observed. initially cultured in the dark for 1 month. Then, the weight of PLBs in each vessel was measured by the electronic balance. The growth or proliferation coefficient of PLBs was calculated based on the weight of PLBs after 1 month of culture divided by the initial weight of PLBs.

For shoot induction, 9 PLBs $\approx 0.3$ to 0.4 $\mathrm{cm}$ in diameter per cultivar were cultured on MS medium supplemented with $0.88 \mu \mathrm{M}$ 6BA, $0.5 \mu \mathrm{M}$ NAA, $30 \mathrm{~g} \cdot \mathrm{L}^{-1}$ sucrose, $0.1 \mathrm{~g} \cdot \mathrm{L}^{-1}$ $\mathrm{AC}$, and $7 \mathrm{~g} \cdot \mathrm{L}^{-1}$ agar with a $\mathrm{pH}$ of 5.8 . The experiment was an RCBD with 10 vessels per block and a total of 3 blocks. They were maintained under a 12-h photoperiod with light intensity of $20 \mu \mathrm{mol} \cdot \mathrm{m}^{-2} \cdot \mathrm{s}^{-1}$ for 2 months. The initial times of shoot formation
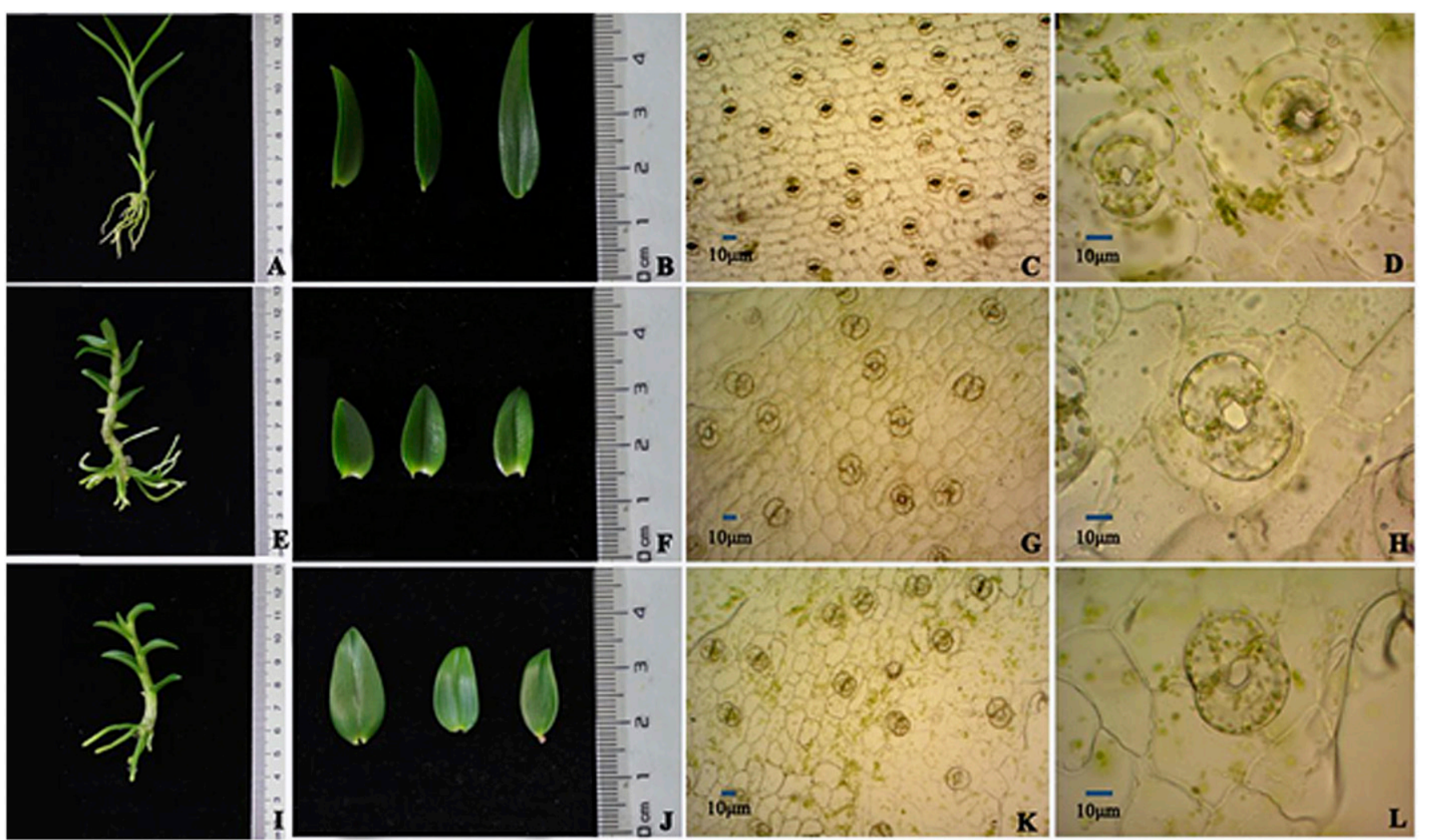

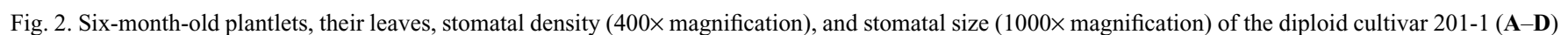
and tetraploid cultivars 201-1-T $(\mathbf{E}-\mathbf{H})$ and 201-1- $\mathrm{T}_{2}(\mathbf{I}-\mathbf{L})$ of D. officinale. 
and root formation were recorded. The numbers of shoots and roots from each PLB were recorded after 2 months of culture.

Analysis of polysaccharides content. To determine the polysaccharide content, an experiment that was the same as the one used for the aforementioned morphological analysis was conducted. After 6 months of growth, polysaccharide contents in leaves, stems, and roots were measured using the standard protocol published by Chinese Pharmacopoeia (Committee for the Pharmacopoeia of P R China, 2015). Briefly, $50 \mathrm{~g}$ of the stems, leaves, and roots of plantlets were placed in a brown envelope and dried in an electrical oven at 60 to $65^{\circ} \mathrm{C}$ to a constant weight. After being ground into powder, a $0.3-\mathrm{g}$ sample was mixed in $200 \mathrm{~mL}$ of

Table 2. Induction of PLBs from stem explants of diploid and tetraploid cultivars of D. officinale. ${ }^{\mathrm{z}}$

\begin{tabular}{lcc}
\hline Cultivar & Day PLB initiation & PLB induction rate (\%) \\
\hline $201-1$ & $13.4 \pm 1.20 \mathrm{~b}^{\mathrm{y}}$ & $40.18 \pm 2.95 \mathrm{~b}$ \\
$201-1-\mathrm{T}_{1}$ & $16.6 \pm 0.40 \mathrm{a}$ & $56.03 \pm 7.01 \mathrm{a}$ \\
$201-1-\mathrm{T}_{2}$ & $17.4 \pm 0.74 \mathrm{a}$ & $55.75 \pm 4.42 \mathrm{a}$ \\
\hline
\end{tabular}

${ }^{\mathrm{z}}$ All data represent means \pm SE $(\mathrm{n}=3)$.

${ }^{\mathrm{y}}$ Different letters within the same column indicate a significant difference at $P \leq 0.05$ based on Duncan's multiple range test.

deionized water and refluxed in a syncore parallel reactor (Büchi, Switzerland) for $2 \mathrm{~h}$ at $100{ }^{\circ} \mathrm{C}$; after cooling, the solution was diluted to $250 \mathrm{~mL}$ in volumetric flask. The solution was filtered using a vacuum filter; $2 \mathrm{~mL}$ of filter solution was transferred to a centrifuge tube after adding $7 \mathrm{~mL}$ of absolute ethanol. Then, the tube was kept in refrigeration at $4{ }^{\circ} \mathrm{C}$ for $1 \mathrm{~h}$, followed by centrifuging at $6000 \mathrm{rpm}$ for $20 \mathrm{~min}$ using a centrifuge (Allegra X-15R; Beckman Coulter, Fullerton, CA). After being washed with $8 \mathrm{~mL}$ of $80 \%$ ethanol twice, the precipitate was dissolved in heated water and diluted to $25 \mathrm{~mL}$. Then, $1 \mathrm{~mL}$ of the solution, $1 \mathrm{~mL}$ of $5 \%$ phenol, and $5 \mathrm{~mL}$ of pure sulfuric acid solution were transferred to a $10-\mathrm{mL}$ glass tube and well-mixed. Next, the tube was boiled in boiling water for $20 \mathrm{~min}$. After being cooled
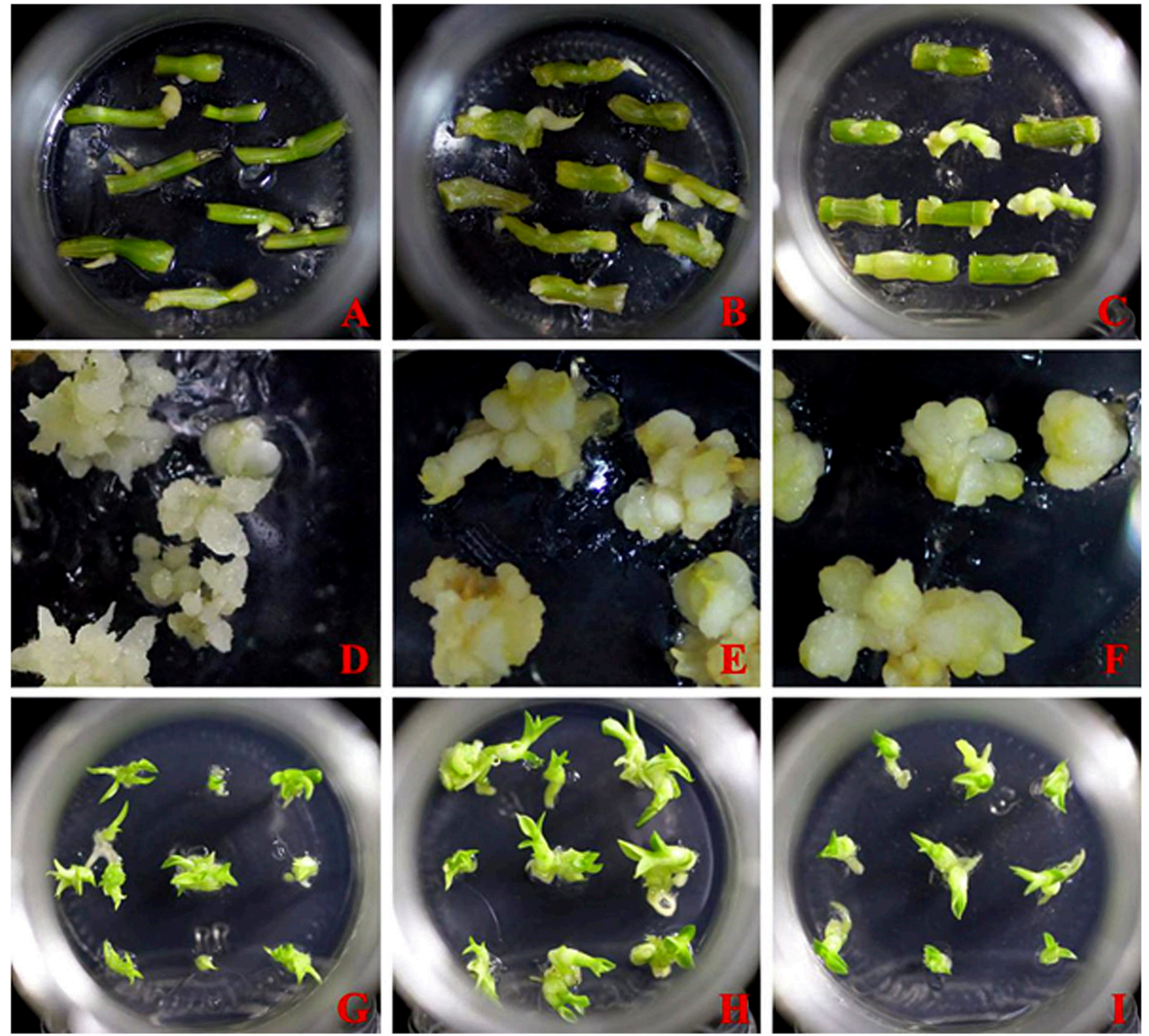

Fig. 3 The induction (A-C) and proliferation (D-F) of protocorm-like bodies (PLBs) and plant regeneration (G-I) from PLBs of the diploid cultivar 201-1 (A, D, G) and tetraploid cultivars 201-1- $\mathrm{T}_{1}(\mathbf{B}, \mathbf{E}, \mathbf{H})$ and 201-1- $\mathrm{T}_{2}(\mathbf{C}, \mathbf{F}, \mathbf{I})$ of D. officinale. 
in ice water for $5 \mathrm{~min}$, the solution was transferred to the cuvette to measure the absorbance with an ultraviolet spectrophotometer. The content of polysaccharides was calculated as glucose in the solution. This experiment was repeated three times.

Statistical analysis. Collected data were subjected to an analysis of variance (ANOVA) using SPSS 13.0 for Windows (SPSS, Chicago, IL). When significant differences occurred, means were separated using Duncan's multiple range test with $P<$ 0.05 considered significant.

\section{Results}

Morphological changes. Two tetra-

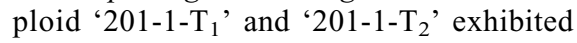
marked differences in several morphological characteristics compared to diploid '201-1' (Table 1). Leaf, stem, and root lengths of the tetraploid cultivars were significantly shorter than that of the diploid cultivar (Fig. 2). The stem and root diameters were much greater than those of the diploid. However, leaf number, leaf width, and root number, were similar among the three cultivars. As a result, fresh weights of the tetraploids were 2-fold higher than those of the diploid (Table 1). The length and width of stomata cells as well as the stomatal area of tetraploid plants were much larger than those of the diploid cultivar, whereas the stomatal density significantly decreased in tetraploid plants (Table 1, Fig. 2).

Differences in PLB induction, proliferation, and regeneration. Significant differences in the induction of PLBs were observed between diploid and tetraploid cultivars. The time required to induce PLBs in the diploid was shorter than that of the tetraploids. The PLB induction rates for tetraploids were $56.03 \%$ and $55.75 \%$ compared with $40.18 \%$ for the diploid (Table 2, Fig. 3A-C). However, there were no significant differences between the two tetraploid lines regarding the PLB induction time and rate.

The proliferation of PLBs among the three cultivars varied significantly. The mass of PLBs produced by the diploid was less compared with that of the two tetraploid cultivars (Fig. 3D-F). The proliferation coefficients of the tetraploid PLBs were significantly higher than that of the diploid: up to 3.69 and 3.03 for the tetraploids compared with 2.31 for the diploid (Fig. 4). Furthermore, tetraploid '201-1- $\mathrm{T}_{1}$ ' exhibited a higher PLB proliferation rate than tetraploid '201-1- $\mathrm{T}_{2}$ '.

Shoot regeneration from PLBs were also different between the diploid and tetraploids
(Table 3, Fig. 3G-I). Shoot initiation took $\approx 14 \mathrm{~d}$ in the diploid but $\approx 16 \mathrm{~d}$ in the tetraploids (Table 3 ). The mean number of shoots regenerated from diploid PLBs was significantly higher than that regenerated from tetraploid PLBs, and the time of root initiation in the diploid occurred much earlier than that in the tetraploids.

Differences in polysaccharide content. The polysaccharide content in stems was much greater than that in leaves, and the content in leaves was higher than that in roots, regardless of ploidy levels. Polysaccharide contents in stems, leaves, and roots of tetraploid cultivars were significantly higher than those in the diploid (Table 4). The contents of polysaccharide in stems, leaves, and roots of '201-1- $\mathrm{T}_{1}$ ' were 2.04-fold, 2.81fold, and 2.22-fold higher than those in the diploid cultivar. Similarly, polysaccharide contents in stems, leaves, and roots of '201$1-\mathrm{T}_{2}$ ' were 1.61-fold, 2.74-fold, and 3.49fold higher than those in the diploid line. Additionally, the polysaccharide contents of the two tetraploids were different. In roots, the polysaccharide content of ' $201-1-\mathrm{T}_{2}$ ' $(2.41 \%)$ was significantly higher than that of ' $201-1-\mathrm{T}_{1}$ ' $(1.53 \%)$; however, in stems, the polysaccharide content of '201-1- $\mathrm{T}_{2}$ ' $(10.03 \%)$ was lower than that of '201-1-T $(12.70 \%)$.

\section{Discussion}

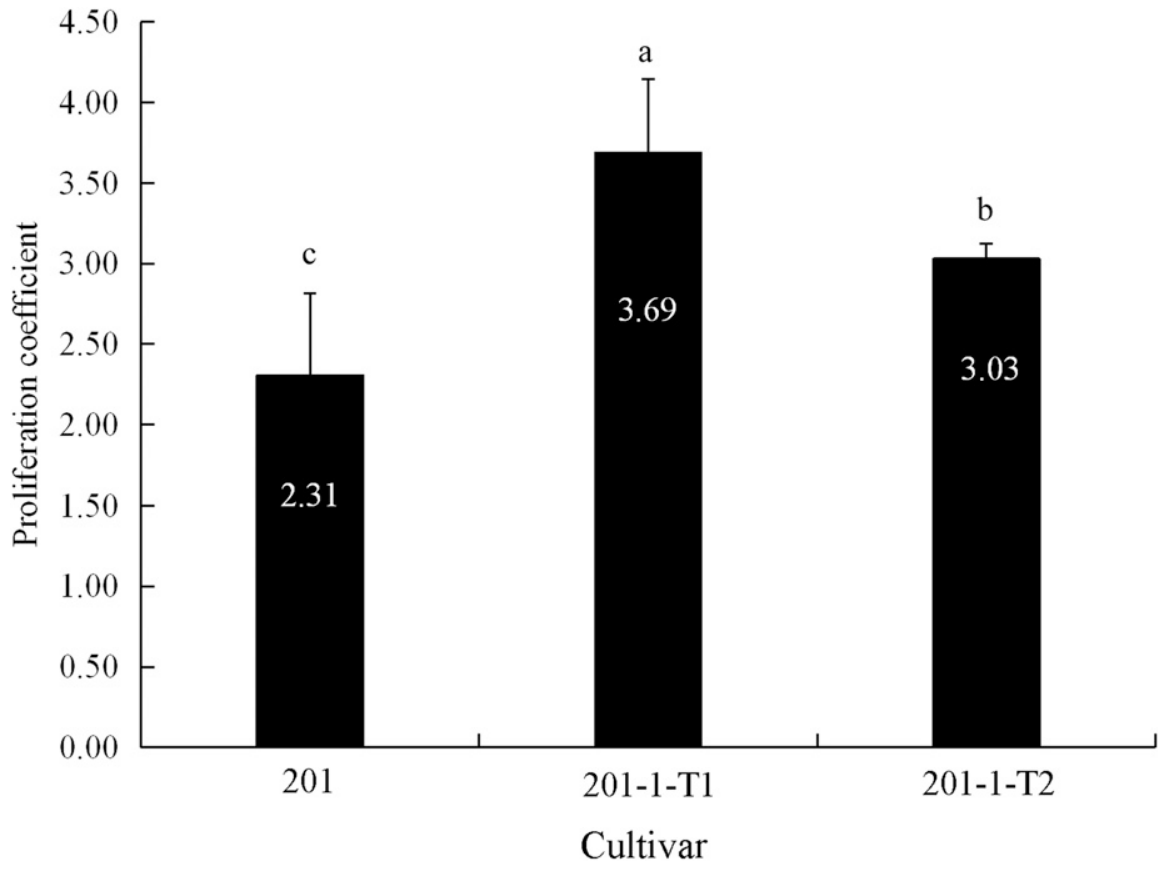

Fig. 4. The proliferation coefficient of the diploid cultivar 201-1 and tetraploid cultivars 201-1- $T_{1}$ and 201$1-\mathrm{T}_{2}$ of $D$. officinale. Bars represent SE, and letters above the bars indicate significant difference at $P \leq$ 0.05 based on Duncan's multiple range test.
Dendrobium officinale is an important ornamental flowering plant worldwide. It is also a famous traditional Chinese medicinal plant. With the increasing recognition of its nutraceutical and pharmaceutical values, production of $D$. officinale in China increased rapidly from 3900 ha in 2014 to 7066 ha in 2016 (Cheng et al., 2019). The increased production acreage was also accompanied by high demand for new cultivars that can produce higher biomass with increased polysaccharide contents. Our research of $D$. officinale developed as a series of cultivars with different ploidy levels. The present study tested our hypothesis that gene abundance due to chromosome doubling could increase biomass production and polysaccharide contents. The results showed that tetraploid cultivars produced significantly higher fresh weights compared with the diploid cultivar. Polyploidization also changed the regeneration ability of tetraploid cultivars. The polysaccharide contents in stems, leaves, and roots of 6-month-old tetraploid plantlets were either nearly doubled or more than doubled in comparison with that of the diploid parental cultivar. Our study showed that chromosomal doubling is a viable way of

Table 3. Shoot regeneration and root formation from protocorm-like bodies (PLBs) of diploid and tetraploid cultivars of D. officinale. ${ }^{\text {z }}$

\begin{tabular}{|c|c|c|c|c|}
\hline Cultivar & Day of initial shoot appearance & Mean number of shoots per PLB & Day of initial root appearance & Mean no. of roots per plantlet \\
\hline$\overline{201-1}$ & $13.90 \pm 0.46 \mathrm{a}^{\mathrm{y}}$ & $2.90 \pm 0.43 \mathrm{a}$ & $28.90 \pm 0.67 b$ & $0.90 \pm 0.23 \mathrm{a}$ \\
\hline $201-1-\mathrm{T}_{1}$ & $16.50 \pm 0.34 b$ & $1.70 \pm 0.15 b$ & $34.30 \pm 0.58 \mathrm{a}$ & $0.70 \pm 0.21 \mathrm{a}$ \\
\hline $201-1-T_{2}$ & $15.80 \pm 0.33 \mathrm{~b}$ & $1.20 \pm 0.13 \mathrm{~b}$ & $33.50 \pm 0.34 \mathrm{a}$ & $0.65 \pm 0.13 \mathrm{a}$ \\
\hline
\end{tabular}

${ }^{\mathrm{z}}$ All data represent means $\pm \mathrm{SE}(\mathrm{n}=3)$

${ }^{\mathrm{y}}$ Different letters within the same column indicate significant difference at $P \leq 0.05$ level based on Duncan's multiple range test. 
Table 4. Polysaccharide contents in diploid and tetraploid plantlets of D. officinale. ${ }^{\mathrm{z}}$

\begin{tabular}{lccc}
\hline Cultivar & Stems (\%) & Leaves (\%) & Roots (\%) \\
\hline $201-1$ & $6.22 \pm 0.05 \mathrm{c}^{\mathrm{y}}$ & $1.59 \pm 0.12 \mathrm{~b}$ & $0.69 \pm 0.08 \mathrm{c}$ \\
$201-1-\mathrm{T}_{1}$ & $12.70 \pm 0.19 \mathrm{a}$ & $4.47 \pm 0.14 \mathrm{a}$ & $1.53 \pm 0.07 \mathrm{~b}$ \\
$201-1-\mathrm{T}_{2}$ & $10.03 \pm 0.14 \mathrm{~b}$ & $4.37 \pm 0.15 \mathrm{a}$ & $2.41 \pm 0.12 \mathrm{a}$ \\
\hline
\end{tabular}

${ }^{\mathrm{z}}$ All data represent means $\pm \mathrm{SE}(\mathrm{n}=3)$.

${ }^{\mathrm{y}}$ Different letters within the same column indicate a significant difference at $P \leq 0.05$ based on Duncan's multiple range test.

improving biomass and polysaccharide production in D. officinale.

Chromosome doubling can lead to various morphological and anatomical changes (Corneillie et al., 2018; Sattler et al., 2016; Tantasawat et al., 2012; Teixeira da Silva et al., 2014a). In the present study, tetraploid plantlets had shorter leaf, stem, and root lengths and thicker stem and root diameters as well as increased fresh weights compared with the diploid, representing a phenomenon called the Gigas effect (Knight and Beaulieu, 2008); in other words, chromosome doubling generally causes increased organ size (Osborn et al., 2003). Therefore, tetraploid plants had significantly higher biomass production (Corrêa et al., 2016; Hannweg et al., 2016). Additionally, stomatal size was significantly increased but stomatal density was decreased in tetraploid plants. It has been reported that the number of guard cells per unit area decreased in accordance with the increased level of polyploidy (De Oliveira et al., 2004). Some early studies considered that the lower frequency of stomata in tetraploids was probably due to the larger epidermal and guard cells (Gantait et al., 2011; Mishra. 1997) as well as reduced stomata differentiation ( $\mathrm{Tu}$ et al., 2018). This phenomenon has also been documented for Salvia miltiorrhiza (Gao et al., 1996), Agastache foeniculum (Talebi et al., 2017), and Anoectochilus formosanus (Chung et al., 2017).

The current study also showed that chromosome doubling changed the regeneration ability through PLBs. The time for PLB initiation from tetraploid stem nodes was longer than that for the diploid. However, the induction rate was higher compared with that of the diploid. Polyploidization can lead to an increased number of internodes (Vichiato et al., 2014). PLBs are generally induced from the nodes of stems. We believe that the increased PLB induction rate could be due to the increased stem nodes in tetraploid plantlets. As a result, the proliferation coefficients of tetraploid PLBs were higher compared with that of the diploid, which was similar to the results of Xie et al. (2017), who indicated that the proliferation rates of tetraploid PLBs were higher than those of triploids and diploids in Cymbidium hybridum. This is likely related to the increased cell size of tetraploid plantlets. The time required for shoot appearance from PLBs increased, but the number of shoots produced per PLB piece was reduced in tetraploid cultivars. These results concurred with the results of Sun et al. (2011), who indicated that the polyploid in Pyrus communis was accompanied by reduced in vitro shoot and root organogenesis. The failure of completing cytokinesis (Øvrebø and Edgar, 2018) or difficulty progressing through normal mitosis (Comai, 2005) can result in decreased in vitro organogenesis polyploids. Additionally, chromosome doubling causes chromosomal rearrangements, inversions, translocations, and even loss or retention of the duplicated genes (Blanc and Wolfe, 2004). The rearrangement might directly or indirectly affect regeneration ability (Colijn-Hooymans et al., 1994; Kubalakova et al., 1996; Lin et al., 2001).

In vitro polyploidization has a significant role in boosting vigor and metabolite contents in medical plants (Salma et al., 2017), such as overaccumulated shihunidine content in tetraploid PLBs of Dendrobium hybrid (Grosso et al., 2018), higher polysaccharide and phenolic compounds in tetraploid pseudobulbs of Bletilla striata (Li et al., 2018b), richer stevioside in mixoploids leaves of Stevia rebaudiana (Hegde et al., 2015), and superior baicalin content in tetraploid roots of Scutellaria baicalensis (Gao et al., 2002). Polysaccharide is the major active component in D. officinale (Song et al., 2016), and it has an important role in healing some diseases (Luo et al., 2017; Xie et al., 2016). In this study, tetraploid plantlets produced significantly higher polysaccharide contents in leaves, stems, and roots than diploid plantlets. The results suggested that young plantlets produce abundant polysaccharide, as documented by Yuan et al. (2017), and that the polysaccharide contents in tetraploid plantlets were much higher than those in diploid parental plantlets. Similar results were also reported by Jiang et al. (2014). The increased polysaccharide may be partly attributable to the increased cell size and, thus, thicker leaves and roots of tetraploid plantlets, as mentioned by Hegde et al. (2015). The overexpression of genes following chromosome doubling can also enhance secondary metabolites (Comai, 2005; Majdi et al., 2014; Yun-Soo et al., 2004). Recently, Corneillie et al. (2018) reported that polyploidization in Arabidopsis thaliana was associated with a proportional reduction in secondary cell wall deposition, such as lignin and cellulose, and concomitantly increased other cell wall polysaccharides. Whether the cell composition changes have contributed to the increased polysaccharides in the tetraploids '201-1- $\mathrm{T}_{1}$ ' and ' $201-1-\mathrm{T}_{2}$ ' requires further investigation. Nevertheless, our study demonstrated that chromosome doubling represents a workable approach to increasing biomass and polysaccharide production in
D. officinale, and its application could potentially increase the supply of $D$. officinale materials for commercial use.

\section{Literature Cited}

Alonso-Sande, M., D. Teijeiro-Osorio, C. RemuñánLópez, and M.J. Alonso. 2009. Glucomannan, a promising polysaccharide for biopharmaceutical purposes. Eur. J. Pharm. Biopharm. 72:453-462.

Atichart, P. 2013. Polyploid induction by colchicine treatments and plant regeneration of Dendrobium chrysotoxum. Thai J. Agr. Sci. 46:59-63.

Blanc, G. and K.H. Wolfe. 2004. Functional divergence of duplicated genes formed by polyploidy during Arabidopsis evolution. Plant Cell 16:1679-1691.

Cakova, V., F. Bonte, and A. Lobstein. 2017. Dendrobium: Sources of active ingredients to treat age-related pathologies. Aging Dis. 8: 827-849.

Chaicharoen, S. 1995. Studies on chromosome number, floral and characteristic fertility of diploid and allotetraploid Dendrobium superbiens. Kasetsart J. Natl. Sci. 29:150-157.

Chaicharoen, S. and K. Saejew. 1981. Autopolyploidy in Dendrobium phalaenopsis. J. Sci. Soc. Thailand 7:25-32.

Chen, J. and X. Wei. 2018. Thidiazuron in micropropagation of aroid plants, p. 95-113. In: N. Ahmad and M. Faisal (eds.). Thidiazuron: From urea derivative to plant growth regulator. Springer Nature Singapore Pte Ltd., Singapore.

Chen, X., L. Tian, T. Shan, L. Sun, and S. Guo. 2018. Advances in germplasm resources and genetics and breeding of Dendrobium officinale. Acta Pharm. Sinica 53:1493-1503 (In Chinese with English abstract).

Chen, X.M., F.F. Wang, Y.Q. Wang, X.L. Li, A.R. Wang, C.L. Wang, and S.X. Guo. 2012. Discrimination of the rare medicinal plant Dendrobium officinale based on naringenin, bibenzyl, and polysaccharides. Sci. China Life Sci. 55:1092-1099.

Cheng, J., P. Dang, Z. Zhao, L. Yuan, Z. Zhou, D. Wolf, and Y. Luo. 2019. An assessment of the Chinese medicinal Dendrobium industry: Supply, demand and sustainability. J. Ethnopharmacol. 229:81-88.

Chung, H.H., S.K. Shi, B. Huang, and J.T. Chen. 2017. Enhanced agronomic traits and medicinal constituents of autotetraploids in Anoectochilus formosanus Hayata, a topgrade medicinal orchid. Molecules 22:1-13.

Colijn-Hooymans, C.M., J.C. Hakkert, J. Jansen, and J.B.M. Custers. 1994. Competence for regeneration of cucumber cotyledons is restricted to specific developmental stages. Plant Cell Tissue Organ Cult. 39:211-217.

Comai, L. 2005. The advantages and disadvantages of being polyploidy. Nat. Rev. Genet. 6:836846.

Committee for the Pharmacopoeia of PR China. 2015. Pharmacopoeia of PR China, Part I. China Medical Science and Technology Press, PR China (in Chinese).

Corneillie, S., N. De Storme, R. Van Acker, J.U. Fangel, M. De Bruyne, R.M. De Rycke, D. Geelen, W.G.T. Willats, B. Vanholme, and W.A. Boerjan. 2018. Polyploidy affects plant growth and alters cell wall composition. Plant Physiol. 179:74-87.

Corrêa, J.P.O., C.E. Vital, M.V.M. Pinheiro, D.S. Batista, C.W. Saldanha, A.C.F. da Cruz, M.M. Notini, D.M.S. Freitas, F.M. DaMatta, and W.C. Otoni. 2016. Induced polyploidization increases 20-hydroxyecdysone content, in vitro 
photoautotrophic growth, and ex vitro biomass accumulation in Pfaffia glomerata (Spreng.) Pedersen. In Vitro Cell. Dev. Biol. Plant. 52: 45-55.

Cui, J., J. Chen, and R.J. Henny. 2009. Regeneration of Aeschynanthus radicans via direct somatic embryogenesis and analysis of regenerants with flow cytometry. In Vitro Cell. Dev. Biol. Plant 45:34-43.

Cui, J., J. Liu, M. Deng, J. Chen, and R.J. Henny. 2008. Plant regeneration through protocormlike bodies induced from nodal explants of Syngonium podophyllum 'White Butterfly'. HortScience 43:2129-2133.

De Oliveira, V.M., E.R. Forni-Martins, P.M. Magalhães, and M.N. Alves. 2004. Chromosomal and morphological studies of diploid and polyploid cytotypes of Stevia rebaudiana (Bertoni) Bertoni (Eupatorieae, Asteraceae). Genet. Mol. Biol. 27:215-222.

del Pozo, J.C. and E. Ramirez-Parra. 2014. Deciphering the molecular bases for drought tolerance in Arabidopsis autotetraploids. Plant Cell Environ. 37:2722-2737.

Ding, G., D. Zhang, X. Ding, Q. Zhou, W. Zhang, and X. Li. 2008. Genetic variation and conservation of the endangered Chinese endemic herb Dendrobium officinale based on SRAP analysis. Plant Syst. Evol. 276:149-156.

Dou, M.M., Z.H. Zhang, Z.B. Li, J. Zhang, and X.Y. Zhao. 2016. Cardioprotective potential of Dendrobium officinale Kimura et Migo against myocardial ischemia in mice. Mol. Med. Rep. 14:4407-4414.

Dudits, D., K. Török, A. Cseri, K. Paul, A.V. Nagy, B. Nagy, L. Sass, G. Ferenc, R. Vankova, P. Dobrev, I. Vass, and F. Ayaydin. 2016. Response of organ structure and physiology to autotetraploidization in early development of energy willow Salix viminalis. Plant Physiol. 170:1504-1523.

Gantait, S., N. Mandal, S. Bhattacharyya, and P.K. Das. 2011. Induction and identification of tetraploids using in vitro colchicine treatment of Gerbera jamesonii Bolus cv. Sciella. Plant Cell Tissue Organ Cult. 106:485-493.

Gao, S.L., B.J. Chen, and D.N. Zhu. 2002. In vitro production and identification of autotetraploids of Scutellaria baicalensis. Plant Cell Tissue Organ Cult. 70:289-293.

Gao, S.L., D.N. Zhu, Z.H. Cai, and D.R. Xu. 1996. Autotetraploid plants from colchicine-treated bud culture of Salvia miltiorrhiza Bge. Plant Cell Tissue Organ Cult. 47:73-77.

Grosso, V., A. Farina, D. Giorgi, L. Nardi, G. Diretto, and S. Lucretti. 2018. A highthroughput flow cytometry system for early screening of in vitro made polyploids in Dendrobium hybrids. Plant Cell Tissue Organ Cult. 132:57-70.

Hannweg, K., G. Visser, A. Sippel, and I. Bertling. 2016. Micropropagation and in vitro polyploidisation of Siphonochilus aethiopicus (wild ginger) and its effect on selected horticultural characteristics. Acta Hort. 1113: 175-181.

He, C., K. Wu, J. Zhang, X. Liu, S. Zeng, Z. Yu, X. Zhang, J.A. Teixeira da Silva, R. Deng, J. Tan, J. Luo, and J. Duan. 2017. Cytochemical localization of polysaccharides in Dendrobium officinale and the involvement of DoCSLA6 in the synthesis of mannan polysaccharides. Front. Plant Sci. 8:173, doi: 10.3389/fpls. 2017.00173.

He, T.B., Y.P. Huang, L. Yang, T.T. Liu, W.Y. Gong, X.J. Wang, J. Sheng, and J.M. Hu. 2016. Structural characterization and immunomodulating activity of polysaccharide from
Dendrobium officinale. Intl. J. Biol. Macromol. 83:34-41.

Hegde, S.N., C.N. Rameshsing, and M. Vasundhara. 2015. Characterization of Stevia rebaudiana Bertoni polyploids for growth and quality. Med. Plant 7:188-195.

Hossain, M.M., R. Kant, P.T. Van, B. Winarto, S. Zeng, and J.A. Teixera da Silva. 2013. The application of biotechnology to orchids. Crit. Rev. Plant Sci. 32:69-139.

Jiang, J.L., W. Ye, Y.Q. Li, J.J. Zhou, F.G. Lei, and D.Z. Wei. 2014. Growth and polysaccharides accumulation in autotetraploid Dendrobium officinale. Plant Physiol. J. 50:519-526 (in Chinese with English abstract).

Jin, Q., C.Y. Jiao, S.W. Sun, C. Song, Y.P. Cai, Y Lin, H.H. Fan, and Y.F. Zhu. 2016. Metabolic analysis of medicinal Dendrobium officinale and Dendrobium huoshanense during different growth years. PLoS One 11:1-17.

Ketsa, S., A. Uthairatanakij, and A. Prayurawong. 2001. Senescence of diploid and tetraploid cut inflorescences of Dendrobium 'Caesar'. Scientia Hort. 91:133-141.

Knight, C.A. and J.M. Beaulieu. 2008. Genome size scaling through phenotype space. Ann. Bot. 101:759-766.

Kubalakova, M., J. Dolezel, and A. Lebeda. 1996. Ploidy instability of embryogenic cucumber (Cucumis sativus L.) callus culture. Biol. Plant. 38:475-480.

Lam, Y., T.B. Ng, R.M. Yao, J. Shi, K. Xu, S.C.W. Sze, and K.Y. Zhang. 2015. Evaluation of chemical constituents and important mechanism of pharmacological biology in Dendrobium plants. Evid. Based Complement. Alternat. Med. 2015:841752, doi: 10.1155/2015/841752.

Li, H., X.S. Zheng, and C.L. Long. 2005. Induction of polyploid of Dendrobium devonianum. Acta Bot. Yunnanica 27:552-556 (In Chinese with English abstract).

Li, J., S.W. Gale, P. Kumar, J. Zhang, and G. Fischer. 2018a. Prioritizing the orchids of a biodiversity hotspot for conservation based on phylogenetic history and extinction risk. Bot. J. Linn. Soc. 186:473-497.

Li, M., B. Ding, W. Huang, J. Pan, Z. Ding, and F. Jiang. 2018b. Induction and characterization of tetraploids from seeds of Bletilla striata (Thunb.) Reichb.f. BioMed Res. Intl. Article ID 3246398, doi: 10.1155/2018/3246398.

Lin, H., P.D. Carvalho, D. Kho, C.Y. Tai, P. Pierre, G.R. Fink, and D. Pellman. 2001. Polyploids require Bik1 for kinetochore-microtubule attachment. J. Cell Biol. 155:1173-1184.

Liu, Q., J. Chen, R.T. Corlett, X. Fan, D. Yu, H. Yang, and J. Gao. 2015. Orchid conservation in the biodiversity hotspot of southwestern China. Conserv. Biol. 29:1563-1572.

Luo, D., C. Qu, G.S. Lin, Z.B. Zhang, J.H. Xie, H.B. Chen, J.L. Liang, C.L. Li, H.F. Wang, and Z.R. Su. 2017. Character and laxative activity of polysaccharides isolated from Dendrobium officinale. J. Funct. Foods 34:106-117.

Majdi, M., G. Karimzadeh, and M.A. Malboobi. 2014. Spatial and developmental expression of key genes of terpene biosynthesis in feverfew (Tanacetum parthenium). Biol. Plant. 58:379384.

McConnell, J. and H. Kamemoto. 1993. Morphology and meiotic behavior of three Dendrobium Amphidiploids and their diploid counterparts. Hortscience 28:935-937.

Mishra, M.K. 1997. Stomatal characteristics at different ploidy levels in Coffea L. Ann. Bot. 80:689-692.

Morel, G.M. 1960. Producing virus-free cymbidiums. Amer. Orchid Soc. Bull. 29:495-497.
Murashige, T. and F. Skoog. 1962. A revised medium for rapid growth and bioassays with tobacco tissue cultures. Physiol. Plant. 15:473497.

Øvrebø, J.I. and B.A. Edgar. 2018. Polyploidy in tissue homeostasis and regeneration. Development 145:1-16.

Osborn, T.C., J. Chris-Pires, J.A. Birchler, D.L. Auger, Z.F. Chen, H. Lee, L. Comai, A. Madlung, R.W. Doerge, V. Colot, and R.A. Martienssen. 2003. Understanding mechanisms of novel gene expression in polyploids. Trends Genet. 19:141-147.

Qian, X., C. Wang, T. Ouyang, and M. Tian. 2014. In vitro flowing and fruiting in culture of Dendrobium officinale Kimura et Migo. (Orchidaceae). Pak. J. Bot. 46:1877-1882.

Salma, U., S. Kundu, and N. Mandal. 2017. Artificial polyploidy in medicinal plants: Advancement in the last two decades and impending prospects. J. Crop Sci. Biotechnol. 20:9-19.

Sattler, M.C., C.R. Carvalho, and W.R. Clarindo. 2016. The polyploidy and its key role in plant breeding. Planta 243:281-296.

Song, T.H., X.X. Chen, S.C.W. Tang, J.C.M. Ho, L.X. Lao, and T.B. Ng. 2016. Dendrobium officinale polysaccharides ameliorated pulmonary function while inhibiting mucin-5AC and stimulating aquaporin-5 expression. J. Funct. Foods 21:359-371.

Stoddard, E.M. 1965. Identifying plants by epidermal characters. Conn. Agr. Exp. Stat. Circ. 227.

Sun, Q., H. Sun, R.L. Bell, H. Li, and L. Xin. 2011. Variation of phenotype, ploidy level and organogenic potential of in vitro regenerated polyploids of Pyrus communis. Plant Cell Tissue Organ Cult. 107:131-140.

Talebi, S.F., M.J. Saharkhiz, M.J. Kermani, Y. Sharafi, and F. Raouf Fard. 2017. Effect of different antimitotic agents on polyploid induction of anise hyssop (Agastache foeniculum L.). Caryologia 70:184-193.

Tang, H.X., T.W. Zhao, Y.J. Sheng, T. Zheng, L.Z. Fu, and Y.S. Zhang. 2017. Dendrobium officinale Kimura et migo: A review on its ethnopharmacology, phytochemistry, pharmacology, and industrialization. Evid. Based Complement. Altern. Med. Article ID 7436259 , doi: 10.1155/2017/7436259.

Tantasawat, P., A. Khairum, W. Chaowiset, and W. Wannajindaporn. 2012. Pronamide-induced polyploidy in rhynchostylis and Dendrobium. Acta Hort. 937:615-620.

Teixeira da Silva, J.A., J.C. Cardoso, J. Dobra'nszki, and S. Zeng. 2015. Dendrobium micropropagation: A review. Plant Cell Rep. 34:671-704.

Teixeira da Silva, J.A., D.T. Giang, J. Dobránszki, S.J. Zeng, and M. Tanaka. 2014a. Ploidy analysis of Cymbidium, Phalaenopsis, Dendrobium and Paphiopedillum (Orchidaceae), and Spathiphyllum and Syngonium (Araceae). Biologia 69:750-755.

Teixeira da Silva, J.A., X. Jin, J. Dobránszki, J. Lu, H. Wang, G. Zotz, J.C. Cardoso, and S. Zeng. 2016. Advances in Dendrobium molecular research: Applications in genetic variation, identification and breeding. Mol. Phylogenet. Evol. 95:196-216.

Teixeira da Silva, J.A., S. Zeng, R.F. Galdiano, Jr., J. Dobra'nszki, J.C. Cardoso, and W.A. Vendrame. 2014b. In vitro conservation of Dendrobium germplasm. Plant Cell Rep. 33:1413-1423.

Tu, H.Y., A.L. Zhang, W. Xiao, Y.R. Lin, J.H. Shi, Y.W. Wu, S.T. Wu, C.H. Zhong, and S.X. Mo. 2018. Induction and identification of tetraploid Hedychium coronarium through thin cell layer 
culture. Plant Cell Tissue Organ Cult. 135:395406.

Vichiato, M.R.M., M. Vichiato, M. Pasqual, D.M. Castro, and L.F. Dutra. 2007. Tetraploidy induction and identification in Dendrobium nobile Lindl (Orchidaceae). Rev. Ciênc. Agron. Fortaleza 38:385-390.

Vichiato, M.R.M., M. Vichiato, M. Pasqual, F.A Rodrigues, and D.M. Castro. 2014. Morphological effects of induced polyploidy in Dendrobium nobile Lindl. (Orchidaceae). Crop Breed. Appl. Biotechnol. 14:154-159.

Wang, A.H., Q.Q. Wu, L. Yang, H.J. Xu, and Z.L. Chen. 2017. Study on polyploid of Dendrobium ochreatum induced by colchicine. J. Southwest Univ. (Natural Science Ed.). 39:55-60 (In Chinese with English abstract).

Wang, K.P., H.X. Wang, Y.G. Liu, W.Z. Shui, J.F. Wang, P. Cao, H.J. Wang, R.X. You, and Y. Zhang. 2018. Dendrobium officinale polysaccharide attenuates type 2 diabetes mellitus via the regulation of PI3K/Akt-mediated glycogen synthesis and glucose metabolism. J. Funct. Foods 40:261-271.

Xie, L., S.S. Zhou, M.G. Wang, R.Z. Zeng, H.R. Guo, and Z.S. Zhang. 2017. Creation and micropropagation of polyploids in Cymbidium hybridum. Acta Hort. 16:107-113.

Xie, S.Z., B. Liu, D.D. Zhang, X.Q. Zha, L.H. Pan, and J.P. Luo. 2016. Intestinal immunomodulating activity and structural characterization of a new polysaccharide from stems of Dendrobium officinale. Food Funct. 7:2789-2799.

Xu, J., Q.B. Han, S.L. Li, X.J. Chen, X.N. Wang, Z.Z. Zhao, and H.B. Chen. 2013. Chemistry, bioactivity and quality control of Dendrobium, a commonly used tonic herb in traditional Chinese medicine. Phytochem. Rev. 12:341367.

Yang, L., S. Shi, and Z.X. Xiang. 2013. In vitro induction, identification and physiological characteristics of autotetraploid Dendrobium officinale. Acta Bot Boreal.-Occident. 33: 2189-2193 (In Chinese with English abstract).

Yuan, Z., G. Cong, and J. Zhang. 2014. Effects of exogenous salicylic acid on polysaccharides production of Dendrobium officinale. S. Afr. J. Bot. 95:78-84.

Yuan, Z.Q., J.Y. Zhang, and T. Liu. 2017. Enhancement of polysaccharide accumulation in Dendrobium officinale by exogenously applied methyl jasmonate. Biol. Plant. 61:438-444.

Yun-Soo, K., H. Eun-Joo, N.M. Hosakatte, and P. Kee-Yoeup. 2004. Effect of polyploidy induction on biomass and ginsenoside accumulations in adventitious roots of ginseng. J. Plant Biol. 47:356-360

Zhan, Z.G. and X.U. Cheng. 2011. Study on colchiploid of Dendrobium officinale induced by colchicines. J. Zhejiang Univ. (Sci. Ed.). 38:321-325 (In Chinese with English abstract). 